\title{
Retrieval of SST Algorithm Coefficients at South China Sea
}

\author{
Ng Hou Guan, Mohd. Zubir Mat Jafri \& Khiruddin Abdullah \\ School of Physics, Universiti Sains Malaysia \\ 11800, Minden, Penang, Malaysia \\ Tel: 60-4-653-3888 E-mail: nghouguan@yahoo.com,mjafri@usm.my,khirudd@usm.my
}

The research is financed by USM grant under Graduate Research Scheme of Research University.

\begin{abstract}
The current operational sea surface temperature (SST) algorithm coefficients were not suitable to be applied at South China Sea. Therefore, the algorithm coefficients that could be specially used for South China Sea were required to be calibrated. The study was conducted to find a set value of MCSST and NLSST algorithm coefficients that were suitable to be used at South China, and also to investigate the effect of the haze to SST algorithm. The calibrated algorithm with the new set of coefficients was proved to give more accurate result compared to SST data calculated by using SST algorithm in ENVI. The SST algorithm of ENVI was cited from the NOAA SST algorithm that applied the global algorithm coefficients. Besides that, the study also showed that the haze would affect the SST algorithm.
\end{abstract}

Keywords: SST, Algorithm coefficients, South China Sea, Calibration, Validation

\section{Introduction}

There are many SST algorithms introduced, but they are the generally multi-channel (MCSST) and nonlinear (NLSST) algorithms. MCSST algorithm was developed by McClain and it is based on linear differences in brightness temperatures. It was NOAA's operational algorithm for several years. The latest NOAA's operational SST algorithm is NLSST algorithm.

In this study, the MCSST and NLSST algorithm coefficients were retrieved at South China Sea. The algorithm coefficients were derived from the regression between the SST in-situ data at China Sea and nearly coincident satellite data. The satellite data used for regression was sensor zenith angle $(\theta)$ and brightness temperature of channel $4\left(T_{4}\right)$ and channel $5\left(\mathrm{~T}_{5}\right)$ for AVHRR image.

The SST data was estimated by MCSST and NLSST algorithms with new calibrated algorithm coefficients. The algorithms were also compared with the SST algorithm of ENVI. The new calibrated algorithm was proved to be more accurate than SST algorithm of ENVI. The validation was done with the SST in-situ data. The RMSE of MCSST and NLSST was 3.13 and 5.54, while the RMSE of SST estimated by SST of ENVI was 9.59. The histograms of the SST in-situ data, SST data calculated by the new calibrated MCSST algorithm, NLSST algorithm and algorithm of ENVI were generated with statistical software, Minitab. The histograms showed that the SST data calculated by MCSST and NLSST algorithm were closer to the SST in-situ data compared with the SST data calculated by SST algorithm of ENVI. The SST maps of MCSST algorithm, NLSST algorithm and algorithm of ENVI were generated. The SST map of in-situ data was interpolated by the software PCI with the input of SST data acquired from the site. The maps were generated so that the distribution of the SST data of each algorithm could be compared visually.

After that, another study was done to investigate the validity of the calibrated SST algorithm after a certain period of time. Besides that, the effect of haze to the algorithm was also investigated. The calibration was done at South China Sea by 13 July 2004, 10 July 05 and 11 July 05 . The validation was done at South China Sea by 12 July 04, 10 Aug 04, 10 July 05, 12 July 05, 12 Aug 05, 13 Aug 05, 6 Sep 06, 7 Oct 06 and 6 Nov 06. The RMSE between the SST data estimated from the algorithm and measured SST data was compared.

The results showed that the new calibrated SST algorithm was applied well throughout the year except the occurrence of the haze.

\section{Data and Methodology}

South China Sea was chosen as the study area. The AVHRR image was acquired from Malaysian Center of Remote Sensing (MACRES). The AVHRR data was obtained with the date of July 12, 2004, and at the time of 03:31 UTC. The 
SST in-situ data obtained from Department of Environment (DOE), Malaysian Meteorology Department (MMD) and project of "Research on the Seas and Islands of Malaysia" (ROSES).

First of all, radiometric calibration was done by converting the digital number to brightness temperature for channel 4 and channel 5 of AVHRR data. After that, the geo-coding and geometrical corrections were performed. The missing data, cloudy and sun-glint pixels, and the land area were masked. The good pixels were only used for SST algorithm coefficients retrieval. The good pixels were pixels free from masking.

The SST in-situ data were then interpolated by using the method of point interpolation with Kriging method by PCI software. The SST in-situ data were used as the input vector layer in PCI algorithm. The data of sensor zenith angle and brightness temperature from AVHRR image and SST data from the image produced by the Kriging algorithm of PCI at coincident location were then calibrated to produce the algorithm coefficients of MCSST and NLSST algorithms. The SST data of new calibrated MCSST and NLSST algorithms were then compared with the SST data calculated by the algorithm of ENVI with the histograms, box-plot and the value root mean square error (RMSE).

After that, the second study was done to investigate the effect of the haze and the validity of the algorithm throughout the year. The AVHRR data was downloaded at the date shown in Table 1 from Comprehensive Large Array-data Stewardship System (CLASS) website. The SST data were acquired from DOE, MMD, ROSES and MODIS website.

The DN on channel 4 and channel 5 of AVHRR file were converted to brightness temperature. All the parameters: brightness temperature and sensor zenith angle and sea surface temperature data were geo-referenced by using a large amount of ground control points (GCP) points appended in the level $1 \mathrm{~b}$ file. The data of brightness temperature and sensor zenith angle from AVHRR file was used. These parameter were then stacked and the subset area of the intersection of these parameter were then extracted.

The tool of Layer Stacking in ENVI V4.4 was used to stack all the parameters with the output file range encompasses file overlap. Then all the bad pixels, cloudy pixels and land pixels were filtered for each file. The land area was colour-coded with green colour, cloud and missing data were in yellow colour and sun-glint area in red colour (Figure $1)$.

The algorithm coefficients were calibrated at 10 July 2004, and then the algorithm coefficients were validated at 12 July 2004, 10 August 2004, 10 July 2005, 12 July 2005, 12 August 2005, 13 August 2005, 6 September 2006, 7 October 2006 and 6 November 2006. After that, the algorithm coefficients were calibrated at 10 July 2005 and 11 July 2005, and then validated at 12 July 2005, 12 August 2005, 13 August 2005, 6 September 2006, 7 October 2006 and 6 November 2006.

The first 50 data of $\mathrm{T}_{4}, \mathrm{~T}_{5}$, and $\theta$ used for algorithm calibration at 10 July 2005 were shown in Table 2 . The first 50 data used for validation the algorithm at 12 July 2005 were shown in Table 3. The algorithm coefficients retrieved after calibration and root mean square difference were calculated.

\section{Result and Discussion}

The MCSST and NLSST algorithm coefficients were retrieved by using regression analysis with statistical software, Minitab. The MCSST algorithm retrieved was:

$\operatorname{MCSST}=\mathrm{a}_{0}\left(\mathrm{~T}_{4}\right)+\mathrm{a}_{1}\left(\mathrm{~T}_{4}-\mathrm{T}_{5}\right)+\mathrm{a}_{2}\left(\mathrm{~T}_{4}-\mathrm{T}_{5}\right)(\operatorname{Sec} \theta-1)+\mathrm{a}_{3}$

where the algorithm coefficients:

$$
\mathrm{a}_{0}=0.231, \mathrm{a}_{1}=-1.20, \mathrm{a}_{2}=-2.15, \mathrm{a}_{3}=240
$$

The NLSST algorithm retrieved was:

NLSST $=b_{0}\left(T_{4}\right)+b_{1}\left(T_{4}-T_{5}\right)(M C S S T)+b_{2}\left(T_{4}-T_{5}\right)(\operatorname{Sec} \theta-1)+b_{3}$

where the algorithm coefficients:

$\mathrm{b}_{0}=0.183, \mathrm{~b}_{1}=0.00282, \mathrm{~b}_{2}=-0.26, \mathrm{~b}_{3}=249$

The histograms of SST calculated by MCSST algorithm, NLSST algorithm, ENVI's algorithm and SST in-situ data were shown in Figure 2. The MCSST data was approximately in the range of $27^{\circ} \mathrm{C}$ and $31^{\circ} \mathrm{C}$, while the NLSST data was approximately in the range of $24^{\circ} \mathrm{C}$ and $36^{\circ} \mathrm{C}$. However the range of SST data calculated by algorithm of ENVI was approximately in the range of $15^{\circ} \mathrm{C}$ and $30^{\circ} \mathrm{C}$. The range value of ENVI's SST was obviously shifted to the left compared to SST in-situ data that was in the range of 27 to $36^{\circ} \mathrm{C}$. The MCSST was in the range inside the SST in-situ data. The range of NLSST data was quite similar with the SST in-situ data if compared with other algorithms.

The box plots were then generated (Figure 3). The SST data estimated by the algorithm of ENVI was obviously lower than SST in-situ data. Besides that, the algorithm also generated many outliers that were illogically out of the bound. Overall, the SST data estimated MCSST and NLSST algorithms were better to be used to estimate SST in-situ data.

The RMSE of each algorithm was then calculated. The RMSE of MCSST and NLSST was 3.13 and 5.54, while the 
RMSE of SST estimated by SST of ENVI was 9.59. The comparatively low value of RMSE for MCSST and NLSST algorithms showed they were more accurate than ENVI's algorithm. This was because the ENVI's algorithm not specially designed for the area of South China Sea. However the calibrated MCSST and NLSST algorithms were specially designed for South China but had no guarantee can be used for other places out of South China Sea.

The SST maps of each algorithm and in-situ data were then generated by ENVI (Figure 4, 5, 6 and 7).

After that the next study done was to calibrate the SST algorithm 10 July 2004, 10 July 2005 and 11 July 2005.

The algorithm calibrated at 10 July 2004 was

$$
\begin{aligned}
& \mathrm{MCSST}=303+0.00114 \mathrm{~T}_{4}+0.0246\left(\mathrm{~T}_{4}-\mathrm{T}_{5}\right)+0.772\left(\mathrm{~T}_{4}-\mathrm{T}_{5}\right)(\operatorname{Sec} \theta-1) \\
& \mathrm{NLSST}=303+0.00113 \mathrm{~T}_{4}+0.000081\left(\mathrm{~T}_{4}-\mathrm{T}_{5}\right) \mathrm{MCSST}+0.772\left(\mathrm{~T}_{4}-\mathrm{T}_{5}\right)(\operatorname{Sec} \theta-1)
\end{aligned}
$$

The algorithm calibrated at 10 July 2005

$$
\begin{aligned}
& \text { MCSST }=299+0.0165 \mathrm{~T}_{4}+0.842 *\left(\mathrm{~T}_{4}-\mathrm{T}_{5}\right)-0.221 *\left(\mathrm{~T}_{4}-\mathrm{T}_{5}\right)(\operatorname{Sec} \theta-1) \\
& \mathrm{NLSST}=299+0.0165 \mathrm{~T}_{4}+0.00274 *\left(\mathrm{~T}_{4}-\mathrm{T}_{5}\right) \operatorname{MCSST}-0.219 *\left(\mathrm{~T}_{4}-\mathrm{T}_{5}\right)(\operatorname{Sec} \theta-1)
\end{aligned}
$$

The algorithm calibrated at 11 July 2005

$$
\begin{aligned}
& \mathrm{MCSST}=303+0.0107 \mathrm{~T}_{4}-0.213\left(\mathrm{~T}_{4}-\mathrm{T}_{5}\right)-0.932\left(\mathrm{~T}_{4}-\mathrm{T}_{5}\right)(\operatorname{Sec} \theta-1) \\
& \mathrm{NLSST}=303+0.0108 \mathrm{~T}_{4}-0.000699\left(\mathrm{~T}_{4}-\mathrm{T}_{5}\right) \mathrm{MCSST}-0.934\left(\mathrm{~T}_{4}-\mathrm{T}_{5}\right)(\operatorname{Sec} \theta-1)
\end{aligned}
$$

The RMSE between the SST in-situ and SST estimated by the algorithm calibrated at 10 July 2004, 10 July 2005 and 11 July 2005 was shown in Table 4, Table 5 and Table 6 . The MCSST 1 in the Figure 8 referred to the MCSST algorithm calibrated at 10 July 2004, while the MCCST 2 and MCSST 3 referred to the MCSST algorithm calibrated at 10 July 2005 and 11 July 2005 respectively.

Overall, the RMSE was lower than 2.5, except the date at 6 September and 7 October 2006. This may be due to the effect of South East Asian Haze. The hazy days started around the end of the August 2006 and came to the end around the end of October 2006 as the monsoon season was coming.

The SST algorithms were not applied well at the hazy days. The RMSE was shooting high at 6 September and 7 October 2006, but decreased abruptly at 6 November 2006. Therefore, the SST algorithm was not working well on hazy days. Therefore the new algorithm that was adapted to the changes of the air quality was required to improve the performance of the existing SST algorithm.

The RMSE of MCSST was higher because the algorithm was calibrated by combining AVHRR data at two different times: 02:06 UTC and 03:47 UTC. This might be the source of errors while doing the validation.

\section{Conclusion}

The new calibrated MCSST and NLSST algorithms were more suitable to estimate the SST data compared with the SST in-situ data. It was verified by using the histograms, box plot and RMSE. The RMSE of MCSST and NLSST algorithms were 1.671 and 1.355 respectively. They were far lower compared with RMSE of ENVI's algorithm, 6.797.

Overall, the SST algorithms can be used at South China Sea along the whole year unless the occurrence of haze. The South China that is situated near the equator has an equatorial climate. The equatorial climates do not pronounce four seasons. It is hot and wet throughout the year. The atmosphere parameters were affected only when the occurrence of haze. Therefore the calibrated SST algorithm coefficients were valid to be used along the whole year at South China Sea. However, the SST algorithm coefficients should be recalibrated after the occurrence of haze.

\section{References}

Abdullah, K., Nasirun, M.S., Alui,.B., Ruslan, R., and Yusuff, M. (1997). Cloud Masking Techniques for AVHRR data for Oceanographic Applications in Malaysia., Proceedings of ACRS.

Barton, I.J. (1995) Satellite-derived sea surface temperatures: Current Status, J.Geophys.Res., 100, 8777-8790.

Bindoff, N.L., J. Willebrand, V. Artale, A, Cazenave, J. Gregory, S. Gulev, K. Hanawa, C. Le Quéré, S. Levitus, Y. Nojiri, C.K. Shum, L.D. Talley and A. Unnikrishnan (2007) Observations: Oceanic Climate Change and Sea Level. Climate Change 2007: The Physical Science.

Brisson,A.,P.LeBornge and A. Marsouin.(2002). Determination of SST algorithms for NOAA-17. O\&SI SAF/Low \& Mid Latitudes report.

Buettner, K. J. K. and C. D. Kern (1965). The determination of infrared emissivities of terrestrial surfaces. Geophys.Res., 70, 1329-1337.

Coakley; J.A. and Bretherton, F.P. (1982) Cloud Cover from high-resolution scanner data;detecting and allowing for partially filled of view. Journal of Geophysical Research, 87, 4917-4932. 
Franca, G.B. and Cracknell, A.P. (1994) Retrieval of Land and Sea Surface Temperature using NOAA-11 AVHRR data in northeastern, Brazil. International Journal of Remote Sensing, 15, 1695-1712.

Franca, G.B. and Cracknell, A.P. (1995) A simple cloud masking approach using NOAA AVHRR daytime time data for tropical areas. International Journal of Remote Sensing, 16, 1697-1705.

Kachi, M.H. Murakami, K. Imaoka and A. Shibata (2001) Sea Surface Temperature Retrieved from TRMM microwave imager and visible infrared scanner. J.Meteorol Soc. Japan.

Karl, H.S. (1988). Observations over the Oceans. Satellite Monitoring of the Earth, 148-202.

Kidwell, K. (1991). NOAA Polar Orbital Data User's Guide. NOAA NESDIS Technical Report, USDoC, Washington, DC.

Kidwell, K.B. (1998). NOAA Polar Orbiter Data Users' Guide (TIROS-N, NOAA-6, NOAA-7, NOAA-8, NOAA-9, NOAA-10, NOAA-11, NOAA-12, NOAA-13, NOAA-14) November 1998 Revision. NOAA/ NESDIS/ NCDC.

Kriebel,K.T., Saunders,R.W., Gesell, G. (1989). Optical Properties of Clouds Derived from Fully-Cloudy AVHRR Pixels. Beitr. Phys. Atmosph, 62, 165-171.

Mc Millan, L.M. (1975). Estimation of sea surface temperature from two infrared window measurements with different absorption. J.Geophys.Res, 80, 5113-5117.

Ng, H. G., M. Z. MatJafri, et al. (2008). Improvement on Masking and Flagging Technique on Reducing SST Residual. Aerospace Conference, 2008 IEEE.

Planet, W. G. (ed.) (1988). Data Extraction and Calibration of TIROS-N/ NOAA Radiometers. NOAA Technical Memorandum NESS 107 - Rev. 1 U.S. Department of Commerce, National Oceanic and Atmospheric Administration, Wahington, D.C.

Prabhkara, C. G., Dalu, and V. G. Kunde. (1974). Estimation of sea surface temperature from remote sensing in the 11-13 $\mu \mathrm{m}$ window region. J. Geophys. Res., 79, 5039-5044.

Saunders, P. M. (1967b): Aerial measurement of the sea surface temperature in the infrared. J. Geophys. Res., 72, 4109-4117.

Saunders, P. M. (1968). Radiance at sea and sky in the infrared window 800-1200 cm-I. j. Opt. Soc. Amer., 58, 645- 652.

Saunders, R.W. (1986) An automated scheme for the removal of cloud contamination from AVHRR radiances over western Europe. International Journal of Remote Sensing, 7, 867-886.

Walton, C.C. (1987). Non-linear multichannel algorithms for estimation sea surface temperature with AVHRR satellite data. J. Appl. Meterol, 27, 115-124.

Walton, CC., W.G.Pichel, and J.F. Sapper. (1998). The development and operational application of non-linear algorithms for the measurement of sea surface temperatures with the NOAA polar-orbiting environmental satellites. $J$. Geophysics.Res., 103, 27999-2807.

Wu, X., W.P.Menzel and G.S. Wade. (1999). Estimation of sea surface temperature using GOES-8/9 radiation measurement. BULL. Amer. Meor. Soc., 80, 1127-1138.

Závody, A.M., C.T. Mutlow, and D.T. Llewellyn-Jones. (1995). A radiative transfer model for sea surface temperature retrieval for the Along-Track Scanning Radiometer. J. Geophys. Res., 100, 937-952. 
Table 1. The data and time for the data used in calibration and validation

\begin{tabular}{|l|l|l|}
\hline \multirow{2}{*}{ Date } & \multicolumn{2}{|c|}{ Time } \\
\cline { 2 - 3 } & \multicolumn{1}{|c|}{ AVHRR } & \multicolumn{1}{|c|}{ MODIS } \\
\hline 10 July 2004 & $02: 37$ UTC & $03: 33$ UTC, 03:45 UTC \\
\hline 12 July 2004 & $03: 33$ UTC & $03: 30$ UTC \\
\hline 10 Aug 2004 & $02: 34$ UTC & $03: 00$ UTC \\
\hline 10 July 2005 & $02: 06,03: 47$ UTC & $03: 10$ UTC \\
\hline 11 July 2005 & $03: 28$ UTC & $03: 50 U T C, 03: 55$ UTC \\
\hline 12 July 2005 & $03: 05$ UTC & $03: 00$ UTC \\
\hline 12 Aug 2005 & $02: 58$ UTC & $02: 10$ UTC ,02:15 UTC, \\
\hline 13 Aug 2005 & $02: 35$ UTC & $03: 50$ UTC, 03:55 UTC \\
\hline 6 Sep 2006 & $02: 07$ UTC & $03: 15,03: 20$ UTC \\
\hline 7 Oct 2006 & $01: 56$ UTC & $02: 35$ UTC \\
\hline 6 Nov 2006 & $02: 03$ UTC & $02: 45 U T C$ \\
\hline
\end{tabular}

Table 2. The data used for calibration

\begin{tabular}{|l|c|c|c|c|c|}
\hline latitude & longitude & SST & $\theta$ & $\mathrm{T}_{4}$ & $\mathrm{~T}_{5}$ \\
\hline 4.65637 & 108.111 & 31.56 & 60.4412 & 287.411 & 285.398 \\
\hline 4.65637 & 108.120 & 31.58 & 60.5203 & 287.781 & 285.525 \\
\hline 4.64733 & 108.111 & 31.58 & 60.4412 & 287.535 & 285.271 \\
\hline 4.64733 & 108.120 & 31.60 & 60.5203 & 287.288 & 284.888 \\
\hline 3.51722 & 104.096 & 27.99 & 46.0001 & 281.306 & 279.662 \\
\hline 3.43585 & 104.169 & 33.05 & 46.4749 & 289.702 & 287.253 \\
\hline 3.41777 & 104.151 & 32.75 & 46.4070 & 289.217 & 286.876 \\
\hline 3.40873 & 104.151 & 32.79 & 46.4070 & 289.217 & 286.876 \\
\hline 3.07422 & 104.251 & 31.53 & 47.2246 & 277.524 & 275.201 \\
\hline 3.05614 & 104.242 & 31.74 & 47.2246 & 273.477 & 272.276 \\
\hline
\end{tabular}


Table 2. Continued

\begin{tabular}{|c|c|c|c|c|c|}
\hline latitude & longitude & SST & $\theta$ & $\mathrm{T} 4$ & T5 \\
\hline 3.04710 & 104.242 & 31.79 & 47.2246 & 274.025 & 272.979 \\
\hline 2.81203 & 107.089 & 31.67 & 58.6621 & 289.796 & 287.394 \\
\hline 2.75779 & 107.107 & 31.81 & 58.7387 & 289.326 & 286.897 \\
\hline 2.75779 & 107.116 & 31.75 & 58.7387 & 289.326 & 286.897 \\
\hline 2.75779 & 107.125 & 31.74 & 58.7387 & 289.326 & 286.897 \\
\hline 2.69450 & 105.720 & 31.79 & 53.9015 & 289.891 & 287.403 \\
\hline 2.69450 & 105.729 & 31.82 & 53.9015 & 289.891 & 287.403 \\
\hline 2.68546 & 105.720 & 31.78 & 53.9015 & 289.891 & 287.403 \\
\hline 2.68546 & 105.729 & 31.80 & 53.9015 & 289.891 & 287.403 \\
\hline 2.62217 & 107.308 & 31.57 & 59.5100 & 287.717 & 285.763 \\
\hline 2.61313 & 107.317 & 31.65 & 59.5100 & 287.717 & 285.763 \\
\hline 2.59505 & 107.326 & 31.79 & 59.5877 & 287.471 & 285.254 \\
\hline 2.58601 & 107.326 & 31.83 & 59.5877 & 287.471 & 285.254 \\
\hline 2.58601 & 107.335 & 31.80 & 59.5877 & 287.471 & 285.254 \\
\hline 2.53177 & 107.381 & 31.68 & 59.8213 & 289.436 & 287.029 \\
\hline 2.53177 & 107.390 & 31.71 & 59.8213 & 289.436 & 287.029 \\
\hline 2.53177 & 107.399 & 31.75 & 59.8213 & 289.436 & 287.029 \\
\hline 2.53177 & 107.408 & 31.78 & 59.8213 & 289.436 & 287.029 \\
\hline 2.46848 & 106.560 & 31.80 & 57.1431 & 267.989 & 265.594 \\
\hline 2.46848 & 106.569 & 31.81 & 57.1431 & 267.989 & 265.594 \\
\hline 2.46848 & 106.578 & 31.82 & 57.1431 & 267.989 & 265.594 \\
\hline 2.46848 & 106.587 & 31.83 & 57.1431 & 267.989 & 265.594 \\
\hline 2.45944 & 104.543 & 32.18 & 49.2281 & 289.808 & 287.398 \\
\hline 2.45944 & 104.552 & 32.16 & 49.2281 & 289.808 & 287.398 \\
\hline 2.45944 & 106.560 & 31.77 & 57.1431 & 256.092 & 254.409 \\
\hline 2.45944 & 106.569 & 31.77 & 57.1431 & 256.092 & 254.409 \\
\hline 2.45944 & 106.578 & 31.78 & 57.1431 & 256.092 & 254.409 \\
\hline 2.44136 & 104.561 & 32.30 & 49.2973 & 288.957 & 286.769 \\
\hline 2.43232 & 104.552 & 32.25 & 49.2973 & 287.110 & 285.117 \\
\hline 2.43232 & 104.561 & 32.25 & 49.2973 & 287.365 & 285.376 \\
\hline 2.42328 & 104.552 & 32.21 & 49.2973 & 289.194 & 286.766 \\
\hline 2.42328 & 104.561 & 32.20 & 49.2973 & 287.110 & 285.117 \\
\hline 2.42328 & 104.570 & 32.17 & 49.3666 & 287.110 & 285.245 \\
\hline 2.41424 & 104.561 & 32.16 & 49.3666 & 287.233 & 284.862 \\
\hline 2.41424 & 104.570 & 32.12 & 49.3666 & 287.233 & 284.862 \\
\hline 2.24246 & 104.077 & 32.31 & 47.3725 & 278.466 & 276.160 \\
\hline 2.23342 & 104.059 & 32.59 & 47.3042 & 277.008 & 274.925 \\
\hline 1.86274 & 107.655 & 31.93 & 61.0826 & 287.860 & 285.503 \\
\hline 1.86274 & 107.664 & 31.95 & 61.0826 & 287.860 & 285.503 \\
\hline 1.86274 & 107.673 & 31.96 & 61.0826 & 287.860 & 285.503 \\
\hline
\end{tabular}


Table 3. The data used for validation

\begin{tabular}{|c|c|c|c|c|c|}
\hline$\theta$ & $\mathrm{T}_{4}$ & $\mathrm{~T}_{5}$ & SST & MCSST & NLSST \\
\hline 40.7447 & 286.513 & 284.207 & 305.36 & 304.887 & 304.914 \\
\hline 40.8106 & 283.760 & 281.359 & 305.51 & 304.806 & 304.833 \\
\hline 46.8051 & 290.408 & 288.255 & 305.52 & 304.724 & 304.751 \\
\hline 46.8051 & 289.197 & 287.380 & 305.57 & 304.927 & 304.954 \\
\hline 42.7756 & 281.340 & 279.654 & 305.79 & 305.082 & 305.108 \\
\hline 36.8272 & 283.097 & 282.130 & 305.18 & 305.598 & 305.626 \\
\hline 35.6009 & 283.717 & 281.482 & 305.85 & 305.081 & 305.107 \\
\hline 8.7984 & 288.704 & 286.260 & 304.10 & 305.541 & 305.569 \\
\hline 34.8929 & 281.560 & 280.833 & 304.95 & 305.709 & 305.737 \\
\hline 55.3492 & 290.513 & 288.129 & 304.73 & 303.915 & 303.942 \\
\hline 55.3492 & 290.392 & 288.004 & 304.73 & 303.910 & 303.937 \\
\hline 55.5702 & 288.816 & 287.133 & 305.07 & 304.525 & 304.552 \\
\hline 32.2772 & 283.975 & 281.892 & 305.02 & 305.240 & 305.267 \\
\hline 55.6439 & 291.101 & 288.645 & 305.02 & 303.824 & 303.851 \\
\hline 55.3492 & 287.823 & 286.136 & 304.98 & 304.527 & 304.554 \\
\hline 55.6439 & 286.217 & 284.736 & 304.92 & 304.681 & 304.708 \\
\hline 55.5702 & 284.008 & 283.056 & 304.89 & 305.154 & 305.181 \\
\hline 55.5702 & 287.251 & 285.748 & 304.86 & 304.677 & 304.704 \\
\hline 55.6439 & 287.251 & 285.748 & 304.83 & 304.673 & 304.699 \\
\hline 55.5702 & 284.008 & 283.056 & 304.80 & 305.154 & 305.181 \\
\hline 55.5702 & 284.008 & 283.056 & 304.77 & 305.154 & 305.181 \\
\hline 55.5702 & 287.251 & 285.748 & 304.75 & 304.677 & 304.704 \\
\hline 55.6439 & 287.251 & 285.748 & 304.71 & 304.673 & 304.699 \\
\hline 55.4964 & 284.008 & 283.056 & 304.71 & 305.157 & 305.184 \\
\hline 55.4964 & 287.374 & 285.367 & 304.75 & 304.216 & 304.242 \\
\hline 55.4964 & 286.509 & 284.857 & 304.77 & 304.535 & 304.562 \\
\hline 55.5702 & 286.509 & 284.857 & 304.77 & 304.530 & 304.556 \\
\hline 55.5702 & 289.574 & 287.514 & 304.78 & 304.185 & 304.211 \\
\hline 55.5702 & 289.574 & 287.514 & 304.79 & 304.185 & 304.211 \\
\hline 55.6439 & 289.574 & 287.514 & 304.80 & 304.178 & 304.205 \\
\hline 55.4228 & 288.844 & 286.508 & 304.80 & 303.934 & 303.960 \\
\hline 55.4964 & 288.844 & 286.508 & 304.80 & 303.927 & 303.953 \\
\hline 55.4964 & 290.541 & 288.140 & 304.80 & 303.885 & 303.911 \\
\hline 55.5702 & 290.541 & 288.140 & 304.80 & 303.877 & 303.904 \\
\hline 55.4964 & 288.844 & 286.508 & 305.58 & 303.927 & 303.953 \\
\hline 55.4964 & 291.382 & 288.887 & 305.49 & 303.806 & 303.833 \\
\hline 55.5702 & 291.382 & 288.887 & 305.39 & 303.799 & 303.826 \\
\hline 54.9091 & 286.974 & 284.991 & 305.06 & 304.282 & 304.308 \\
\hline 59.0439 & 286.453 & 284.864 & 305.84 & 304.328 & 304.355 \\
\hline
\end{tabular}


Table 3. Continued

\begin{tabular}{|c|c|c|c|c|c|}
\hline$\theta$ & $\mathrm{T}_{4}$ & $\mathrm{~T}_{5}$ & $\mathrm{SST}$ & MCSST & NLSST \\
\hline 59.7438 & 289.281 & 286.888 & 304.90 & 303.390 & 303.416 \\
\hline 59.6658 & 289.159 & 286.762 & 304.93 & 303.394 & 303.420 \\
\hline 59.7438 & 288.427 & 286.131 & 305.22 & 303.489 & 303.515 \\
\hline 59.7438 & 288.427 & 286.131 & 305.37 & 303.489 & 303.515 \\
\hline 46.9615 & 283.221 & 281.372 & 305.52 & 304.835 & 304.861 \\
\hline 59.6658 & 288.794 & 286.383 & 305.01 & 303.375 & 303.402 \\
\hline 59.7438 & 289.159 & 286.762 & 304.99 & 303.383 & 303.410 \\
\hline 59.6658 & 289.281 & 286.888 & 304.86 & 303.400 & 303.426 \\
\hline 59.6658 & 289.281 & 286.888 & 304.90 & 303.400 & 303.426 \\
\hline 59.7438 & 288.794 & 286.383 & 304.93 & 303.365 & 303.391 \\
\hline
\end{tabular}

Table 4. The RMSE between SST in-situ and SST estimated by the algorithm calibrated at 10 July 2004

\begin{tabular}{|c|c|c|}
\hline RMSE & MCSST & NLSST \\
\hline 12 July 2004 & $1.074 \mathrm{~K}$ & $1.076 \mathrm{~K}$ \\
\hline 10 August 2004 & $1.667 \mathrm{~K}$ & $1.665 \mathrm{~K}$ \\
\hline 10 July 2005 & $0.890 \mathrm{~K}$ & $0.890 \mathrm{~K}$ \\
\hline 12 July 2005 & $1.215 \mathrm{~K}$ & $1.150 \mathrm{~K}$ \\
\hline 12 August 2005 & $1.238 \mathrm{~K}$ & $1.236 \mathrm{~K}$ \\
\hline 13 August 2005 & $1.220 \mathrm{~K}$ & $1.120 \mathrm{~K}$ \\
\hline 6 September 2006 & $2.846 \mathrm{~K}$ & $2.844 \mathrm{~K}$ \\
\hline 7 October 2006 & $1.785 \mathrm{~K}$ & $1.783 \mathrm{~K}$ \\
\hline 6 November 2006 & $0.914 \mathrm{~K}$ & $0.915 \mathrm{~K}$ \\
\hline
\end{tabular}

Table 5. The RMSE between SST in-situ and SST estimated by the algorithm calibrated at 10 July 2005

\begin{tabular}{|c|l|l|}
\hline RMSE & MCSST & NLSST \\
\hline 12 July 2005 & $0.527 \mathrm{~K}$ & $0.525 \mathrm{~K}$ \\
\hline 12 August 2005 & $1.576 \mathrm{~K}$ & $1.568 \mathrm{~K}$ \\
\hline 13 August 2005 & $2.316 \mathrm{~K}$ & $2.308 \mathrm{~K}$ \\
\hline 6 September 2006 & $3.840 \mathrm{~K}$ & $3.832 \mathrm{~K}$ \\
\hline 7 October 2006 & $3.758 \mathrm{~K}$ & $3.749 \mathrm{~K}$ \\
\hline 6 November 2006 & $1.790 \mathrm{~K}$ & $1.783 \mathrm{~K}$ \\
\hline
\end{tabular}

Table 6. The RMSE between SST in-situ and SST estimated by the algorithm calibrated at 11 July 2005

\begin{tabular}{|c|l|l|}
\hline RMSE & MCSST & NLSST \\
\hline 12 July 2005 & $0.964 \mathrm{~K}$ & $0.952 \mathrm{~K}$ \\
\hline 12 August 2005 & $0.777 \mathrm{~K}$ & $0.784 \mathrm{~K}$ \\
\hline 13 August 2005 & $0.758 \mathrm{~K}$ & $0.773 \mathrm{~K}$ \\
\hline 6 September 2006 & $3.408 \mathrm{~K}$ & $3.434 \mathrm{~K}$ \\
\hline 7 October 2006 & $3.756 \mathrm{~K}$ & $3.784 \mathrm{~K}$ \\
\hline 6 November 2006 & $2.097 \mathrm{~K}$ & $2.123 \mathrm{~K}$ \\
\hline
\end{tabular}




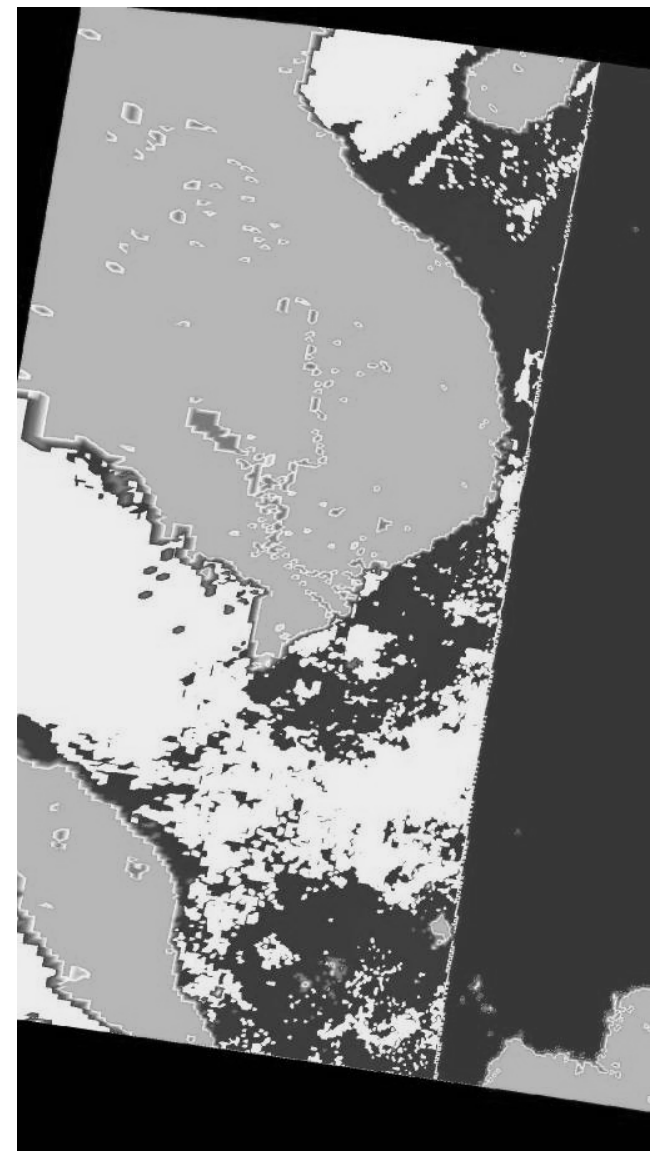

Figure 1. The masking of the land, cloud, sun glint and bad pixels

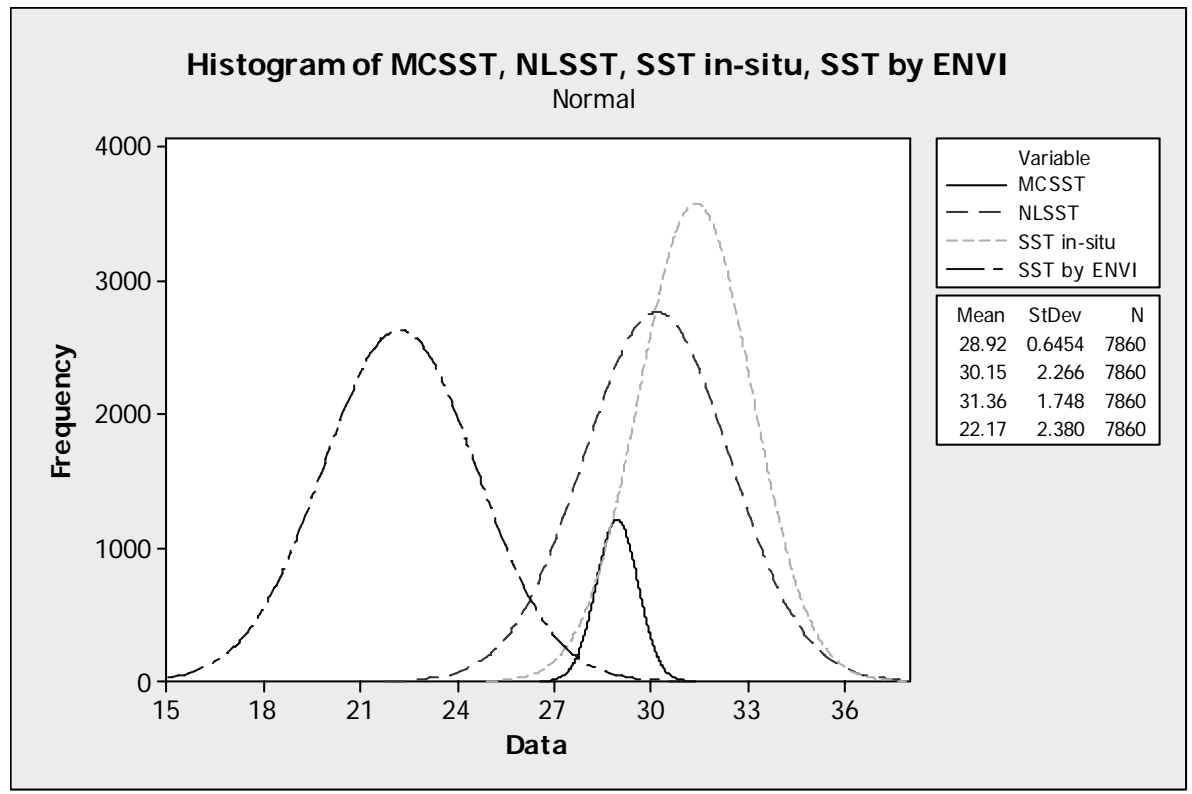

Figure 2. The histograms of SST calculated by MCSST algorithm, NLSST algorithm, ENVI's algorithm and SST in-situ data. 


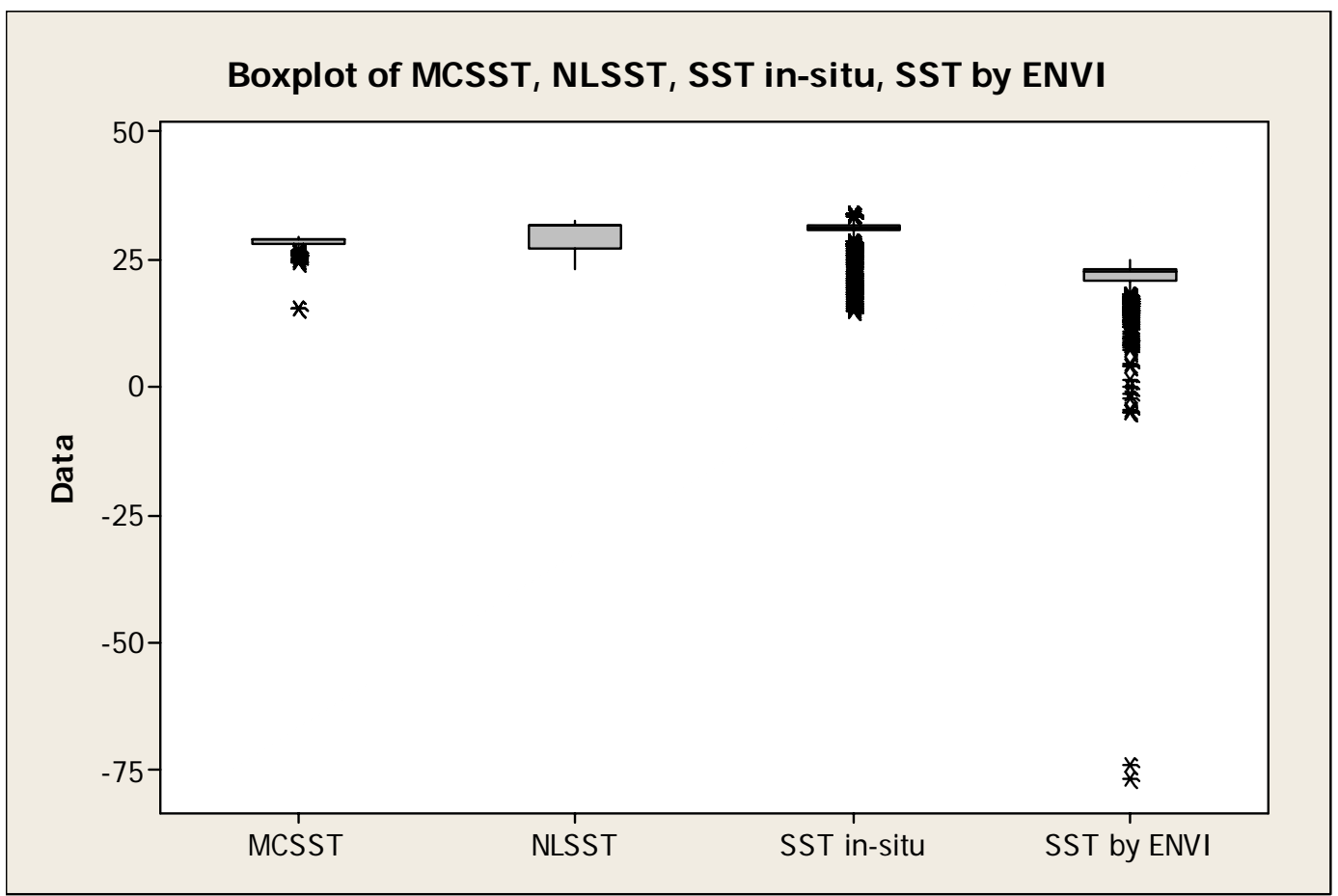

Figure 3. The box plot of SST calculated by MCSST algorithm, NLSST algorithm, ENVI's algorithm and SST in-situ data

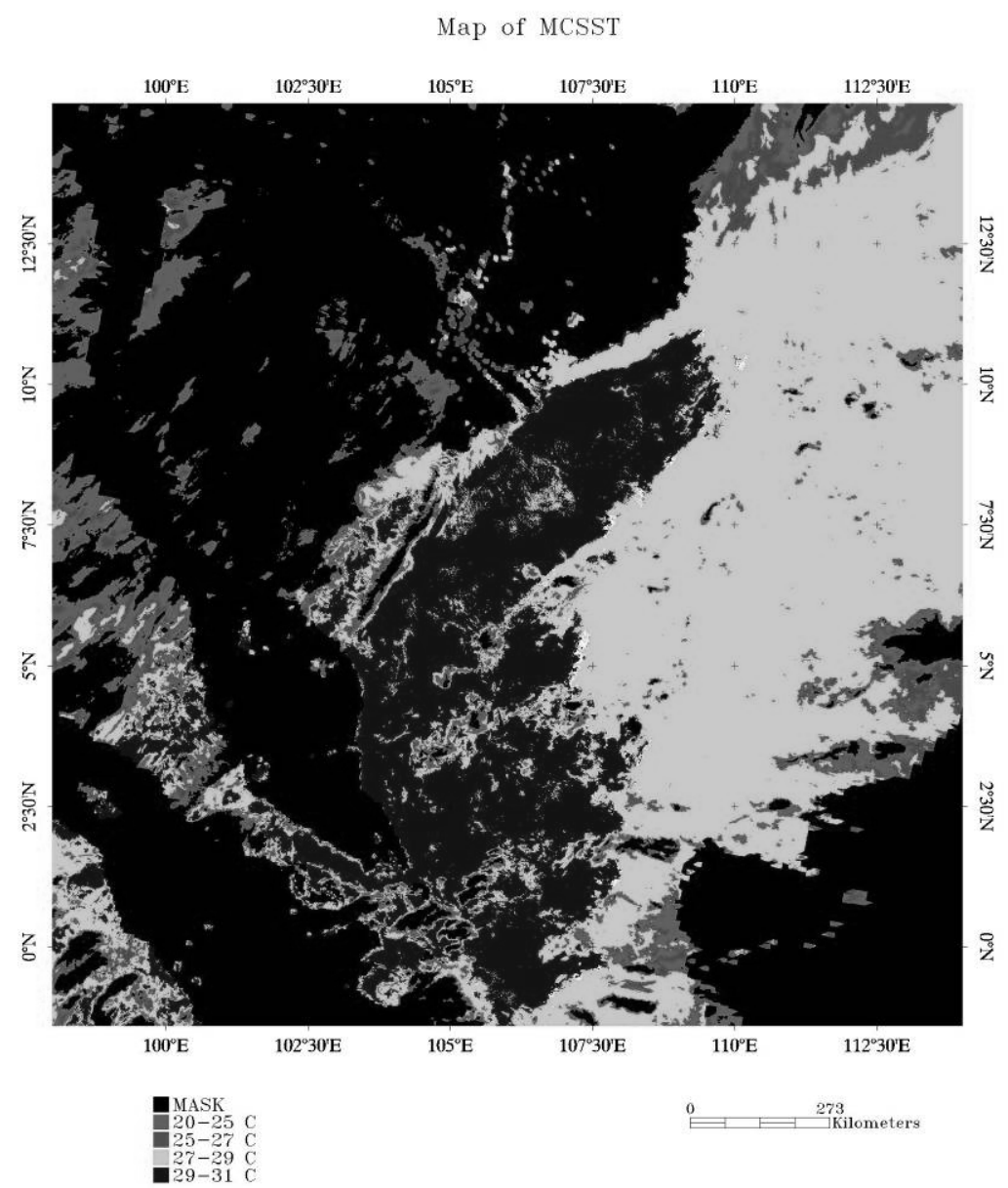

Figure 4. The map of MCSST with new calibrated coefficients 

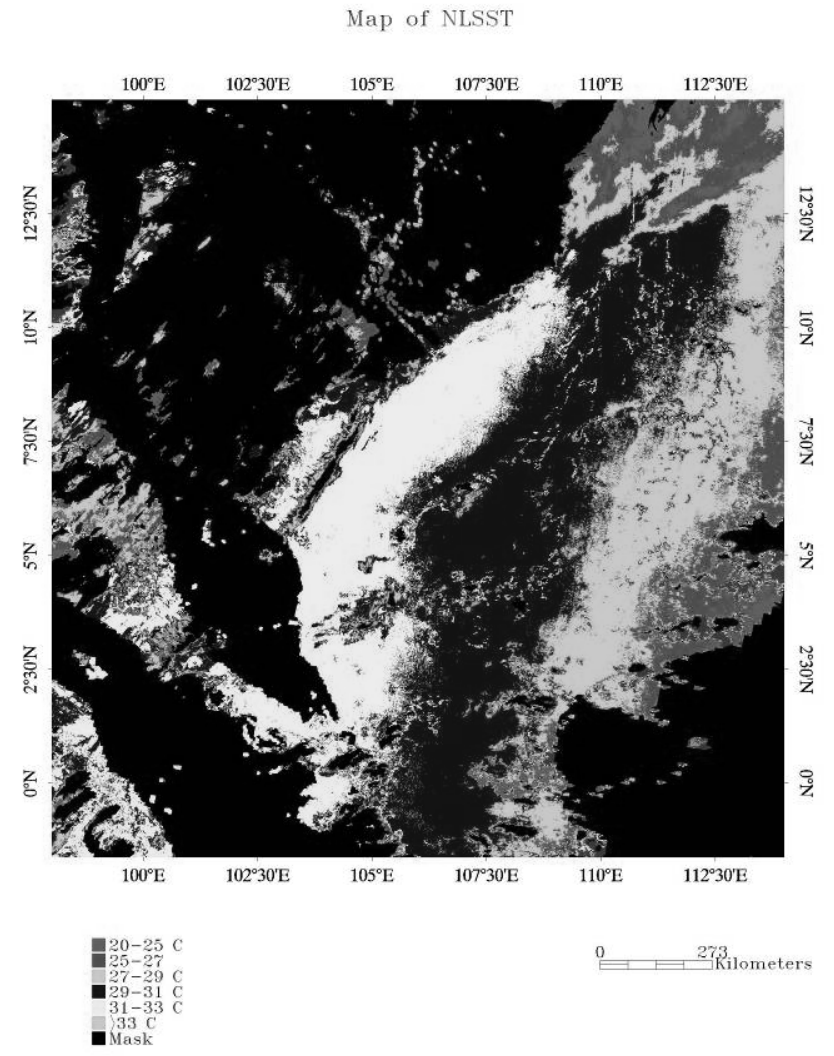

$0 \quad 273$ Kilometers

Figure 5. The map of NLSST with new calibrated coefficients

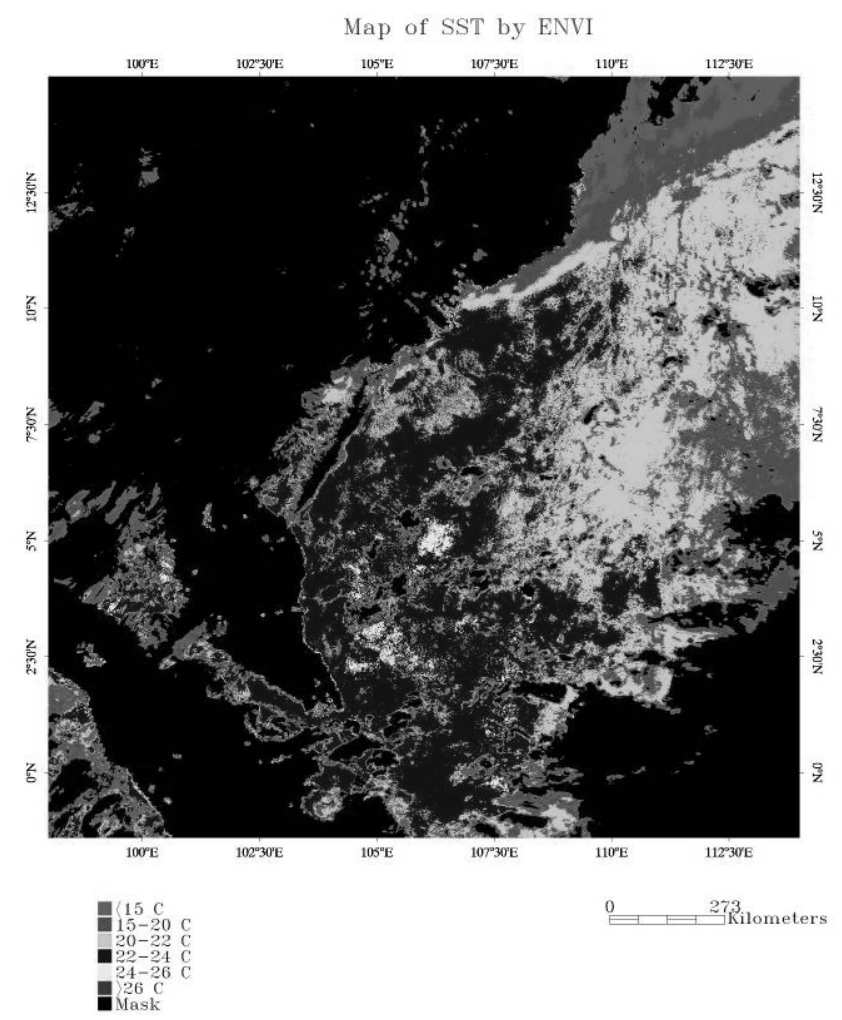

Figure 6. The map of SST generated by ENVI's algorithm 


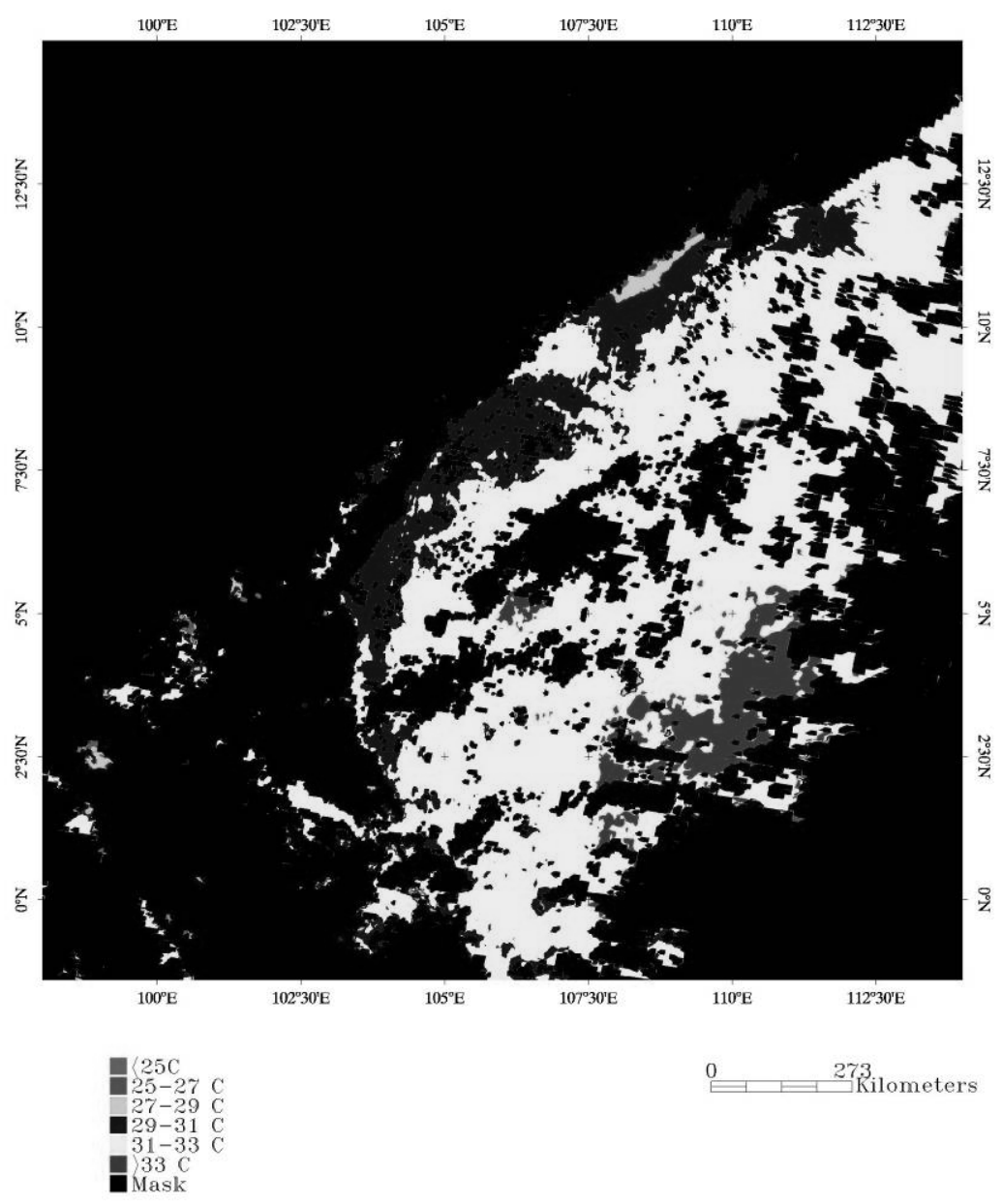

Figure 7. The map of SST generated by of SST in-situ data with Kringing interpolation

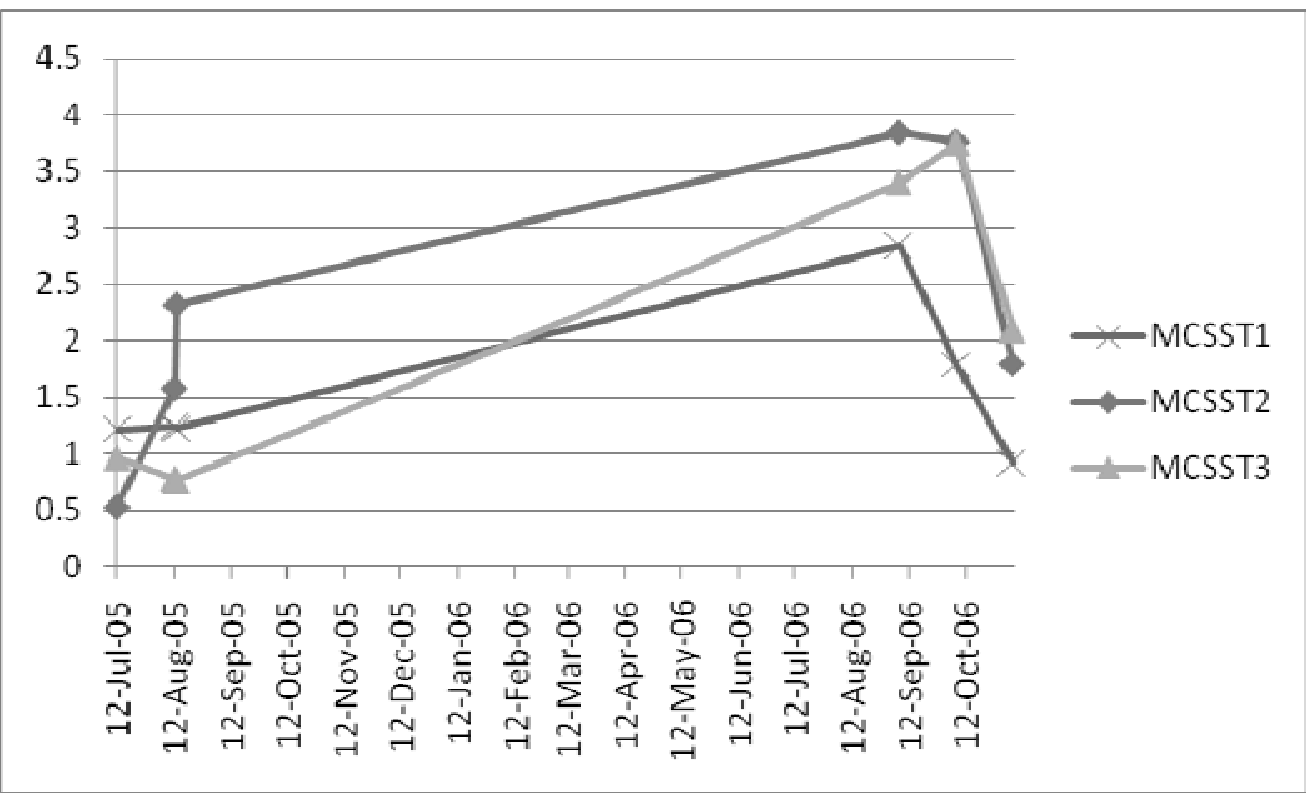

Figure 8 . The trend of RMSE changes with time 